\title{
Sedimentological controls on the formation of high arsenic aquifers in the central Yangtze River Basin since the Last Glacial Maximum
}

\author{
Y. Deng ${ }^{1}$, Y.X. Wang ${ }^{2} \& \mathrm{~T} . \mathrm{Ma}^{2}$ \\ ${ }^{1}$ Geological Survey, China University of Geosciences, Wuhan, China \\ ${ }^{2}$ School of Environmental Studies, China University of Geosciences, Wuhan, China
}

\begin{abstract}
Understanding the mechanism of arsenic mobilization from sediments to groundwater is important for drinking water supply and water quality management in endemic arsenicosis areas, such as the Jianghan alluvial plain in the middle reaches of the Yangtze river. Sediment samples from three boreholes in Jianghan Plain were collected for bulk geochemistry analysis and OSL dating. Sedimentological processes and palaeoclimatic optima after the Last Glacial Maximum have created favorable conditions for the formation of high-As aquifer systems. Bulk sediment geochemistry results indicated that As was correlated with sulfur in the preLGM sediments and by contrast As was correlated with iron in the post-LGM sediments. The intense chemical weathering led to sulfur depletion after the LGM could contribute to the As enrichment in the Holocene and upper Pleistocene aquifer.
\end{abstract}

\section{INTRODUCTION}

Geogenic enrichment of arsenic (As) in groundwater has been a topic worldwide concerned over the past decades due to its severe health threat, which impact about one hundred million people. Within river systems draining the Himalaya, tectonic movement, sedimentological processes and palaeoclimatic optima after the Last Glacial Maximum have created favorable conditions for the formation of high-As aquifer systems mainly within the Late Pleistocene-Holocene deposits (McArthur et al., 2011; Wang et al., 2017). The Jianghan Plain located in the middle reach of the Yangtze River Basin in central China has been documented with severe As contamination in the shallow aquifers (Gan et al., 2014; Deng et al., 2018). However, the underlying mechanism responsible for the formation of high arsenic aquifers has not been clearly understood yet. This purpose of this study was to delineate the relationship between the effects of Quaternary sediment deposition responding to sea level change since the Last Glacial Maximum on the arsenic enrichment in the shallow aquifers in the Jianghan Plain.

\section{METHODS/EXPERIMENTAL}

\subsection{Study area}

Jianghan alluvial plain in Central China is located in the middle Reaches of the Yangtze River, formed by Yangtze River and its largest tributary the Han River (Fig. 1). It is well known as the beautiful and rich land of fish and rice. It has a sub-tropical monsoonal climate with an annual precipitation and evaporation of approximately $1200 \mathrm{~mm}$ and $1378 \mathrm{~mm}$, respectively.

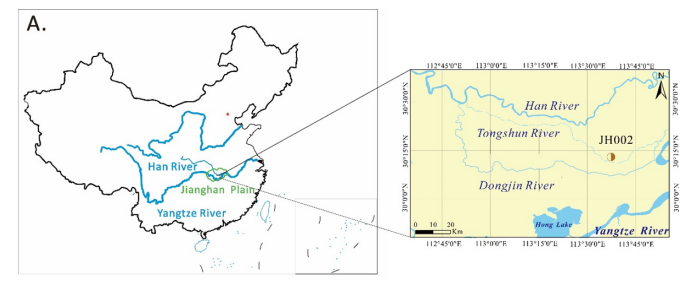

Figure 1. The geographical location of sampling borehole JH002 in the Jianghan Plain.

The Quaternary groundwater systems can be divided into three groups of aquifers. The first group is composed of Holocene alluvial and lacustrine deposits (clay, silt and fine sand) with a thickness of 3-10 m. The second group is composed of late and middle Pleistocene alluvial sediments (medium-coarse sand and gravel, interlaced clay lenses in local area) with a thickness of $30 \mathrm{~m}$; this is the main aquifer for water supply. The third group is composed of early Pleistocene alluvial sediments (fine-medium sand, interlaced clay lenses).

\subsection{Sampling and analysis}

Sediment samples from three boreholes with depths up to $230 \mathrm{~m}$ in typical arsenic-affected area were collected for bulk geochemistry analysis and $\mathrm{As}, \mathrm{Fe}$ and $\mathrm{S}$ speciation. Major-element analysis $\left(\mathrm{SiO}_{2}, \mathrm{Fe}_{2} \mathrm{O}_{3}\right.$, $\mathrm{Al}_{2} \mathrm{O}_{3}, \mathrm{Na}_{2} \mathrm{O}, \mathrm{CaO}, \mathrm{P}_{2} \mathrm{O}_{5}$, and $\mathrm{MgO}$ ) was done with an XRF spectrometer (RIX2100, Rigaku). Trace elements were determined using ICP-MS after a mixed acid $\left(\mathrm{HNO}_{3}-\mathrm{HClO}_{4}-\mathrm{HF}\right)$ digestion. Total carbon and sulfur, total organic carbon were measured using an Elemental Analyzer (Vario MICRO cube, Elementar). 

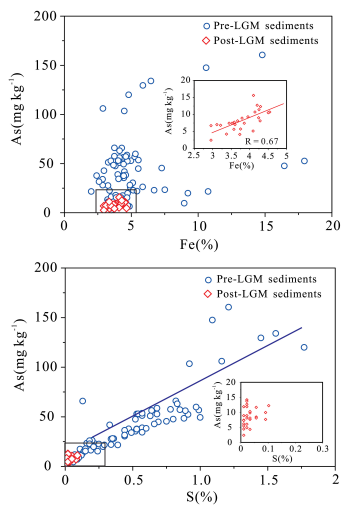

Figure 2. The relationship between arsenic and iron \& sulfur in pre-LGM and post-LGM sediments samples of JH002.

We used the optical stimulated luminescence (OSL) dating method to measure the age of 23 sediment samples with the depths from 3.25 to $45.3 \mathrm{~m}$ below ground surface (bgs).

\section{RESULTS AND DISCUSSION}

\subsection{Lithology and bulk geochemistry}

According to the lithology and grain size analysis, the Quaternary aquifers could be divided into the Holocene-upper Pleistocene phreatic aquifer $(15-60 \mathrm{~m})$ and middle-lower Pleistocene confined aquifer $(>60 \mathrm{~m})$. Bulk sediment geochemistry analysis showed that As, Fe, Mn, P, TOC contents in the sediments of middle-lower Pleistocene aquifer were much higher than those in the Holocene and upper Pleistocene aquifer. Arsenic sequential extraction and SEM-EDS analysis indicated that the shallow sediments possessed an average As content of $9 \mu \mathrm{g} \mathrm{g}^{-1}$. Arsenic content in the groundwater was up to $2330 \mu \mathrm{g}$ $\mathrm{L}^{-1}$. The deep aquifer possessed an average As content of $55 \mu \mathrm{g} \mathrm{g}^{-1}$, and the highest As content in the groundwater was about $100 \mu \mathrm{g} \mathrm{L}^{-1}$. Arsenic was correlated with sulfur in the pre-LGM sediments $(\mathrm{R}=0.7$, $\mathrm{P}<0.05)$ and the pyrite was observed to be the main sink of As in the deep aquifer $(>60 \mathrm{~m})$, by contrast arsenic was correlated with iron in the post-LGM sediments ( $\mathrm{R}=0.67, \mathrm{P}<0.05)$ (Fig. 2).

Iron sequential extraction results indicated that $\mathrm{Fe}$ mainly existed as iron-oxides in Holocene and upper Pleistocene sediments, while the siderite was the main form of in middle-lower Pleistocene sediments. In addition, abundant $\mathrm{Fe}$ in pyrite-form were observed in some sulfur riched samples in middle-lower Pleistocene sediments.

\subsection{Sedimentological controls on the enrichment of arsenic in shallow aquifers since the LGM}

Sea level in the Last Glacial Maximum was $120 \mathrm{~m}$ lower than today, which led to depositional break during 40-20 ka. In warming period, the sea level raised immediately, with a quick response of the Yangtze

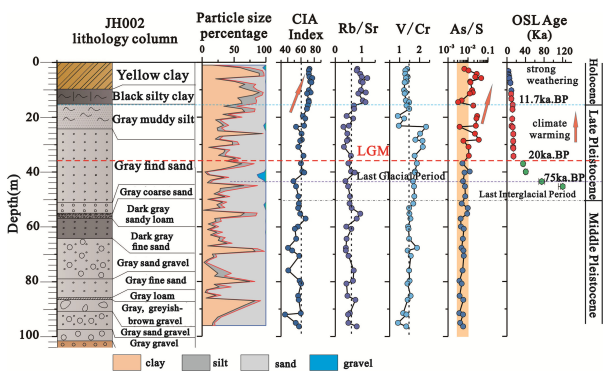

Figure 3. The variation of particle size, CIA index and As/S mole ratio in sediment samples of JH002 borehle.

river. The high $\mathrm{CIA}, \mathrm{Rb} / \mathrm{Sr}$ and $\mathrm{V} / \mathrm{Cr}$ values indicated an intense chemical weathering and oxidizing sedimentary environment in post-LGM period. The mole ratio of $\mathrm{As} / \mathrm{S}$ in the post-LGM sediments was $>0.01$, while in the deep pre-LGM sediments, the As/S kept stable and ranged between 0.0032 and 0.0061 (Fig. 3). Arsenic enriched in the shallow aquifer during post-LGM period may be caused by the intense chemical weathering of arsenopyrite in the sediments after the LGM.

\section{CONCLUSIONS}

The bulk sediments geochemistry indicated that As was correlated with sulfur in the pre-LGM sediments and by contrast arsenic was correlated with iron in the post-LGM sediments. The intense chemical weathering leading to sulfur depletion after the Last Glacial Maximum could contribute to the As enrichment in the Holocene and upper Pleistocene aquifer.

\section{ACKNOWLEDGEMENTS}

The research was financially supported by the National Natural Science Foundation of China (Nos. 41572226 \& 41521001), Program of China Geological Survey (Nos. 121201001000150121).

\section{REFERENCES}

Gan, Y.Q., Wang, Y.X., Duan Y.H., Deng, Y.M., Guo, X.X. \& Ding, X.F. 2014. Hydrogeochemistry and arsenic contami-nation of groundwater in the Jianghan Plain, central China. J. Geochem. Explor. 138(3): 81-93.

Deng, Y.M., Zheng, T.L., Wang, Y.X., Liu, L., Jiang, H.C. \& Ma, T. 2018. Effect of microbially mediated iron mineral transformation on temporal variation of arsenic in the Pleistocene aquifers of the central Yangtze River basin. Sci. Total Environ. 619-620C: 1247-1258.

McArthur, J.M., Nath, B., Banejee, D.M., Purohit, R. \& Grassineau, N. 2011. Palaeosol control on groundwater flow and pollutant distribution: the example of arsenic. Environ. Sci. Technol. 45: 1376-1383.

Wang, Y.X., Pi, K.F., Fendorf, S., Deng, Y.M. \& Xie, X.J. 2017. Sedimentogenesis and hydrobiogeochemistry of high arsenic late pleistocene-holocene aquifer systems. Earth Sci. Rev. DOI:10.1016/j.earscirev.2017.10.007 